\title{
O JOGO DE TÊNIS COMO UMA PRÁTICA A FAVOR DA QUALIDADE DE VIDA NO CAMPO DO ESPORTE DE LAZER
}

\section{THE GAME OF TENNIS AS PRACTICE IN FAVOR OF THE QUALITY OF LIFE IN THE LEISURE OF SPORT FIELD

\author{
Dr. Sergio Stucchi
}

Faculdade de Educação Física/UNICAMP

\begin{abstract}
Resumo
O esporte como elemento do desenvolvimento com suas modalidades como conteúdos culturais - individual e coletivo - intervindo na valorização do tempo livre junto à transformação do trabalho industrial e o aumento dos serviços. No caso do tênis de campo esta interferência é notada nas formas de desenvolvimento do 'esporte de lazer' concorrendo com o esporte profissional. Esta modalidade de esporte, mostra alguns descaminhos quanto aos seus personagens atores em seu processo de ensino e administração de organizações, porém, ganhando acessibilidade por sua desmistificação nas mãos de quem é especialista.

Palavras-Chave: Educação Física; Esporte; Tênis de campo; Lazer; Conteúdo cultural; Organizações esportivas; Certificação de qualidade.
\end{abstract}

\section{Introdução}

Na história de chegada dos jogos populares e das práticas esportivas no Brasil, o tênis de campo é protagonista junto com o futebol e outras. Porém, com muitas diferenças nas formas como se desenvolveram, demonstrando alguns descaminhos que fizeram da prática de oferecimento e de demanda deste jogo especificamente, encontrar grandes barreiras até hoje difíceis de serem transpostas.

Uma comparação simples é o exemplo da necessidade numérica para a formação de um time. Para de um coletivo, os imigrantes necessitavam de maior número de pessoas e convidavam os nativos brasileiros para completar o time, enquanto que para os individuais, apenas seu pequeno grupo já era suficiente. Para que esta afirmação tenha sentido como "conteúdo cultural" de influência, pretendemos situar a modalidade jogo de tênis no campo da sociologia do lazer, baseado na proposta de Joffre Dumazedier (1980). 
Essencialmente estas práticas eram usadas nos períodos de descanso do trabalho das primeiras empreitadas na colonização e construção do país. Disseminou-se a migalhas, até chegar a um estado atual, agora exigindo até a formação de recursos humanos para favorecer sua continuidade para um desenvolvimento sustentável. Com o desenvolvimento da sociedade e seus diversos interesses, podemos visualizar o esporte, através de duas categorias de praticantes hoje reconhecidas: o consumidor de "esporte de lazer" e o trabalhador de "esporte profissional".

$\mathrm{Na}$ formação de uma sociedade capitalista, o trabalho, a seriedade, os compromissos profissionais, sempre determinaram comportamentos, ditando regras de obrigatoriedade, tarefas e metas para o lucro financeiro, ligado a sua denominada lógica concorrencial de mercado. Isto exerceu grandes influências na forma como aprendemos o significado das práticas esportivas, muito próximas dos rendimentos econômicos, de vitórias e derrotas, de sucessos e fracassos, e muito distantes das formas essencialmente humanas de razão de estar praticando esportes, diferentemente como aqui consideramos "esporte de lazer".

Olhando para o nosso dia-a-dia, podemos ver que ainda somos este tipo de sociedade e ainda praticamos o esporte concorrencial, pela forma como vivemos. Corremos todo o tempo atrás do dinheiro, pois, nesta forma de distribuição, somos uma maioria que luta pela sobrevivência em atendimento às mínimas necessidades, com poucos obtendo lucros. Portanto, somos obrigados a justificar nossa subordinação à organização de tempos e espaços, primeiramente para estes valores econômicos e em segundo lugar, para as relações humanas puras e simples do lazer. Uma grande quantidade de tempo para trabalho produtivo, incluindo o esporte profissional ou de espetáculo (TUBINO, 1999), e que vem acompanhado de intenções políticas ideológicas de interesses, e um pequeno período de tempo livre para as relações sociais do "esporte de lazer" (STUCCHI, 2004), como uma dimensão ainda insipiente em nossa cultura de uso dos tempos sociais. Com essa premissa, podemos perceber dois caminhos que o esporte pode nos oferecer.

O processo educativo formal hoje, anuncia igualdades e oportunidades para a busca de autonomia, para o exercício e o consumo das práticas sociais, incluindo as modalidades esportivas. Porém, com esta configuração de um contexto social que 
relaciona a lógica da prática esportiva para o lazer e para o trabalho, como componente de uma cultura estabelecida, encontramos duas categorias de usuários deste esporte: quem planeja, organiza e oferece; e quem aprende e usufrui.

Não haveria problema se os valores não estivessem trocados. A maior demanda tem menor valor, que é para o esporte de lazer, frente ao esporte espetáculo com menor demanda para sua prática, atualmente ainda mais valorizado em razão de sua economia. Entendendo o problema desta forma, devemos voltar nossa atenção para as duas categorias de atores apontadas: os fornecedores, na pessoa dos administradores, professores, instrutores e auxiliares, enquanto diretamente ligados ao esporte pelo trabalho; na categoria de consumidores, dois interesses aparecem: os que são testados e conduzidos por um ensino seletivo para a alta competição, para o espetáculo, vencer a qualquer custo, constantemente ultrapassando limites, a favor de uma economia de negócios, e os que visam a prática do tênis de campo pelo lado da paixão, tendo como premissa, a prática desinteressada, sem pressão, no sentido de um envolvimento humano lúdico de uma prática divertida e de manutenção das qualidades físicas e mentais, aprendendo a conhecer e respeitando seus próprios limites físicos, a favor do enriquecimento da cultura de lazer físico esportivo.

Ao indicar estes seguimentos ligados ao tênis de campo, é nossa pretensão e dever mostrar que este desenvolvimento, de "cultura esportiva", vem necessitando de maior qualidade no oferecimento por parte das organizações, planejando com mais coerência seus conteúdos, indicando objetivos mais claros para seus clientes, que desconhecem os verdadeiras possibilidades da prática do esporte de lazer e, por influência indireta econômica, reconhecem a alta-competição, dando qualidade apenas aos serviços ligados aos eventos para os privilegiados e superdotados.

\section{A Necessidade de uma Descoberta}

A Educação Física como área de conhecimento científico, reconhece o esporte como fenômeno destas diferentes dimensões e aponta a necessidade de uma linguagem mais aprofundada para um diálogo acadêmico. Dentro das novas concepções pelas quais se prevê a manutenção do esporte, são necessárias novas formas de padronização 
a favor da desmistificação de suas imagens, que transformam algumas pessoas em mitos, aumentando o "fosso" (CARVALHO, 1980, p. 69) que existe entre o fenômeno esportivo e o praticante, que se frustra quando não é capaz de atingir o modelo de movimento corporal que é constantemente reforçado pela propaganda. Para tanto, procedimentos de facilitação para seu acesso e de desmistificação devem ser utilizados, mostrando imagens mais comuns de um praticante simples o possível, com estruturas de oportunidades de fácil acesso para democracia da prática e a garantia de manutenção constante destes valores através de programas com objetivos de acompanhamento destas mudanças sociais.

\section{Metodologia}

Para a compreensão e atendimento dessas perspectivas de consumo de esporte e seus significados, é fundamental a exigência, cada vez maior, de recursos humanos com capacitação técnica e conscientes destes valores.

No campo do lazer, será através de pesquisas com reconhecimento da realidade através de diagnósticos cientificamente organizados e planos de aplicação, que essas necessidades, entendidas como fundamentais da população, devam ser atendidas. Observações atentas serão elementos indicadores de procedimentos que, em parceria com os administradores e empreendedores, através de práticas bem dosadas, educativas, participativas e quando for o caso, espetaculares ou de alto rendimento, deverão estabelecer áreas de atuação e limites para as práticas do esporte de lazer, distribuindo formas de organização esportiva na busca de melhora da qualidade de vida.

Nestes levantamentos propostos, vamos deparar com uma posição intermediária e indefinida no campo do tempo livre. Consumidores que se situam dentro da prática do esporte com rendimento atlético, do treinamento para a competição, subordinados às adaptações orgânicas, com planejamento técnico tático e mental, porém, tudo dentro do mais puro amadorismo e ligado as manifestações festivas, sazonais e tradicionais. Para o atendimento destas manifestações, será necessário, além de uma administração profissional, com planejamento, direção, controle e avaliações de conteúdo, para que os limites corporais sejam estabelecidos, recursos físicos, materiais e humanos sob um 
controle e um gerenciamento eficaz, com técnicos e instalações de alta qualidade para atender as características da competição amadora de lazer.

\subsection{Entender as necessidades dos clientes}

Dentre todas as instituições reconhecidas em nossa estrutura sócio-cultural, a educativa formal na figura da escola e das praças públicas municipais são, sem dúvida, as únicas instituições que garantiriam a obrigatoriedade e a gratuidade, respectivamente, da aprendizagem e das experiências através dos conteúdos culturais das práticas esportivas. Bastando para isso, que este conteúdo fosse contemplado em seus recursos programáticos. Neste ponto de vista, no campo das oportunidades, intervir nesse processo, tem significado maior dentre todas as investidas profissionais principalmente quanto à formação de recursos humanos para garantir que este oferecimento ocorra realmente.

Apesar disso, todas as organizações reconhecidas em nossa estrutura social atual, deverão buscar reconhecer seu público alvo com a maior clareza possível. Para tanto, diagnosticar é necessário e isto significa iniciar investigação para, em função das descobertas, se planeje e aplique benefícios aos sujeitos da aprendizagem, através de suas estruturas de oferecimento. Um trabalho de campo será mais bem aproveitado se realizado por uma Administração Científica onde serão solicitados profissionais das áreas específicas de Administração, Pedagogia, Educação Física, Marketing, Arquitetura e Urbanismo, sob supervisão desses próprios profissionais.

A indicação da necessidade de trabalho com profissionais de formação específica, fundamenta-se nas preocupações que dizem respeito ao fenômeno da corporeidade, entendido aqui como de "entrega total" por parte dos clientes, que confiam no trabalho e se entregam, de corpo e alma, para os agentes das ações. Os sujeitos do processo que se submetem às experiências de aprendizagem da modalidade esportiva, envolvendo toda uma gama de situações com esforços físicos e mentais, merecem respeito e atendimento profissional.

De uma simples adaptação dos músculos da mão e do antebraço para a preensão e transporte da raquete, com esforço muscular localizado, até um grande esforço cárdio- 
respiratório, necessário para a disputa de um ponto demorado, atingindo uma freqüência cardíaca elevada. Além disso, submetem-se à exposições mentais dentro de situações de disputa por pontos, desde a simples "troca de bolas" desinteressada, até a necessidade de se decidir sobre que atitude pessoal tomar frente à "violação de código de conduta" pelo adversário, na disputa de numa grande final em âmbito local, estadual, nacional ou internacional. No campo social, estas ações garantirão a congregação de crianças, jovens, adultos e se possível idosos nas mesmas propostas lúdicas esportivas.

Certamente numa organização que tem o jogo de tênis como produto de oferecimento, com seu planejamento de atuação elaborado por dirigentes, proprietários, diretores voluntários e gerentes em parceria com especialistas das áreas, terão sucesso no atendimento da população que busca estes serviços, desde que coerente com as necessidades mostradas pelo diagnóstico levantado, com antecedência, por um plano de trabalho.

No Brasil estivemos diante de uma situação que perdurou por um tempo em que o desenvolvimento do jogo de tênis perseguiu apenas de um dos objetivos da nossa área de conhecimento específico, ou seja, o treinamento visando a alta competição. O que vemos agora é seu resgate voltado para os interesses do esporte de lazer. Este competidor foi, por muito tempo, o estereótipo de uma prática herdada e contaminada pela mentalidade do capitalismo, do alto rendimento, apreendida por poucos e dominada por leigos.

Foi assim com o jogo de tênis de campo na visão da Educação Física, como grande área responsável pelo movimento corporal e pela condução de elementos de uma cultura de prática esportiva. $\mathrm{O}$ reconhecimento desta situação exigiu, estratégias, e continuará a demonstrar necessidades de envolvimento profissional, que contemple elementos de uma pedagogia adaptada para diferentes realidades, considerando as dimensões do ensino formal e não formal, com a certeza de uma prática coerente, cautelosa e melhor distribuída pelas organizações que podem se responsabilizar pela democratização de sua prática: os espaços públicos em todas as suas dimensões. 


\section{Certificação}

Diante de uma sociedade se reorganizando, ainda observamos contrastes fortes quanto aos diferentes níveis sociais, de oportunidades, de escolaridade e conseqüentemente de práticas relativas aos conteúdos culturais. Nosso sistema escolar ainda classifica, diferencia e dá oportunidades hierarquizadas para diferentes grupos sociais em função do poder de compra. Nada mais coerente e justo dentro de um sistema capitalista neoliberal. Porém, pouco democrático e ético. Ao mesmo tempo em que se divulga o jogo de tênis pela grande mídia, gerando uma expectativa, em nada é aumentado seu oferecimento que deveria ser proporcional, através de espaços específicos.

Dentro desta perspectiva, uma outra crítica feita sobre nosso desenvolvimento, diz respeito aos recursos humanos responsáveis pelo crescimento do interesse na prática. Refiro-me a personagens importantes desta história, voluntários, pessoas altamente motivadas e interessadas em colaborar no processo, mas que não tiveram oportunidade de engajamento no sistema como profissionais das áreas já indicadas. Sentem-se necessários, participantes, porém, despreparados e explorados para o exercício profissional. Refiro-me a uma classe de pessoas que estiveram junto ao processo de ensino e aprendizagem como auxiliares (como nos tempos dos colonizadores imigrantes) e que, em razão do tempo em trabalho no ambiente, aprenderam a manuseio dos materiais e, de forma inconsciente e estereotipada, utilizase apenas de seqüências de movimentos necessários a realização do jogo. A grande mudança que ocorre atualmente é a surgimento de "Órgãos Certificador de Qualidade", em defesa do consumidor, de nossa área específica, que canalizará interesses dos futuros auxiliares, aprendizes ou entusiastas da prática, a evoluírem desta condição, para a de um profissional da área, através do processo formal de conhecimentos, se assim o desejarem.

\section{A Sociedade e o Ciclo Vital}

O jogo de tênis tem sua identidade com peculiaridades próprias ganhando elementos relativos aos seus praticantes. Desde a chegada, dos primeiros imigrantes no 
Brasil, elementos antropológicos de uma cultura de movimentos corporais (DAOLIO, 2004) já apareceram como componentes importantes no universo específico desta prática. Naturalmente o envolvimento entre os diferentes personagens da história, imigrantes europeus, índios nativos brasileiros e escravos africanos, criou um movimento de características próprias e isto nos fez únicos numa concepção corporal específica de um povo, configurando também uma cultura de movimentos própria.

Essa evolução de comportamentos é observada numa seqüência temporal de crescimento e desenvolvimento do homem, apresentando passagens "da primeira para a terceira idade" (PARKER, 1973, p. 60), com experiências de acordo com as necessidades de cada uma delas. As modalidades esportivas como elementos culturais desse processo, auxiliam grandemente quando utilizadas coerentemente dentro dos campos das atividades individuais e coletivas com experiências controladas de envolvimentos.

Nas diferentes formas de classificar os esportes em: educacional, espetacular, competitivo, participativo e recreativo, Parker nos ajuda em sua Sociologia do Lazer, mostrando o ciclo vital em fases da vida que se completam. Este estudo nos ajuda a entender o jogo esportivo considerado dentro desta seqüência de etapas, junto às outras esferas de envolvimento.

Apesar de todas as mudanças anunciadas, como sociedade industrial capitalista, ainda vivemos sob uma grave disfunção do ideal educativo, ou seja, formar cidadãos para o trabalho, aptos a responderem as exigências de um mercado competitivo. Conseqüentemente, este preceito interfere nas decisões de gerenciamento quanto aos recursos humanos e financeiros dentro das administrações nos âmbitos das organizações públicas e privadas. Em havendo ainda uma cumplicidade entre a escola para a vida e a escola para o trabalho, a educação para a primeira fase do ciclo infância - forma a crianças apenas para competir e compreende o início da educação para a vida, valorizando mais o trabalho e menos o tempo livre.

Num segundo momento da infância, o "modelo" exige que o adolescente seja preparado para os papeis do adulto, passando pela transição considerada difícil e problemática. É um período em que a educação para os hábitos tem grande possibilidade de ser condicionada, pouco pelos costumes da família, muito pelos 
conteúdos culturais da escola e muito mais pelo meio ambiente que contém elementos de influência dos amigos e a mídia.

Nesta perspectiva os esportes são estabelecidos culturalmente, como poderia ser o caso do jogo de tênis, ocupando o tempo de lazer. Na evolução do processo de escolaridade, as perspectivas de vencer cada etapa influenciam nas atitudes de compromisso do jovem na organização de seus tempos de estudo como trabalho e das outras atividades. As estruturas da escola ainda exercem pressões crescentes quanto a competição para obter sucesso nas avaliações escolares do conteúdo cognitivo em detrimento do conteúdo motor, que se tornará fator limitante para o tempo disponível do lazer esportivo.

$\mathrm{Na}$ segunda idade do ciclo vital ou a idade adulta, é o período de maior ocupação com atividades no cotidiano. É também chamada de "idade doméstica" onde o estado civil com paternidade, é categoria de grande influência nas tarefas dos tempos liberados do trabalho profissional. Esta condição vai mudando assim que os filhos crescem, se desenvolvem e ganham autonomia.

$\mathrm{Na}$ categoria de adulto solteiro, dependendo da formação de valores éticos, sociais, intelectuais e econômicos adquiridos, aparecem outros conteúdos que concorrem com a prática do esporte. $\mathrm{O}$ chamado anti-lazer que se caracteriza no consumo de práticas pouco saudáveis, surgindo com a força da propaganda. Nesta mesma linha se pode arriscar uma discussão sobre a "tecnologia" e o "bar" que, mal utilizados, criam condição excessivamente passiva e prejudicial respectivamente de uso do tempo livre, chegando pesadamente através de aparelhos eletrônicos que fascinam a imaginação e elementos etílicos que distorcem as idéias.

$\mathrm{Na}$ terceira idade, a cada nova descoberta da biologia e da fisiologia, a longevidade da população é aumentada. A Medicina terapêutica, a Educação Física preventiva, está cada vez mais atuante na cura das doenças e na melhora da qualidade de vida da população. Aqueles que, por sorte e gozando de uma boa saúde, associado à conquista do período da aposentadoria socializada ou planejada, vem se caracterizando como uma grande parcela da população de usuários do lazer esportivo.

Para cada uma dessas fases da vida, ainda existe um período de tempo correspondente às suas obrigações frente aos compromissos do dia-a-dia da sociedade 
industrial. Os dependentes do trabalho profissional têm como tempo livre a ser preenchido, o final do dia, o fim-de-semana, o fim do ano nas férias e, ainda sob a legislação atual o fim da vida como aposentadoria. Estes são períodos de tempo primeiramente ligado ao processo produtivo do trabalho e depois aos conteúdos do lazer, coincidentes com as faixas etárias e elementos de grande importância para o planejamento das atividades físicas e esportivas das organizações que se propõem a oferecimento do esporte que complete os afazeres de uma sociedade em período de reorganização.

\section{O Esporte, a Sociedade e a Educação}

Nesse desenvolvimento social, aparece o esporte como conteúdo cultural ligado a produção a partir de meados do século XIX, com suas mudanças de significados junto a outras necessidade sociais, ganhando sistematizações e importância. Segundo Dunning (1986), foi quando o resgate do "Ideal Olímpico" norteou a participação nas práticas esportivas de forma a realçar o espírito cívico, moral e confraternizante dos jogos esportivos. Três dimensões sociais do esporte ainda são atualmente consideradas importantes para que possamos entender nossa participação e ainda não estão totalmente contempladas nas atuais conjunturas de políticas públicas e privadas.

O principal descaminho que se cria com o sentido educativo do esporte, é sua utilização como atividade de rendimento através de formas seletivas de ação. Vamos buscar em Carvalho (1998, p.13) se referindo a construção de uma ética do futuro, considerando muitos fenômenos, podemos ligar ao esporte que não pode ficar apenas

[...] territorializado como está, parece que o conhecimento ainda se nega a enfrentar desafios, porque parece contente consigo mesmo, encastelado em seus espaços de vigilância, narcisismo e punição, obcecado por avaliações, verbas, siglas e prebenbas.

Essencialmente para a Educação Física é importante retomar as características do esporte de lazer que nos foram legadas e, que precisam ser ampliadas e atualizadas em sintonia com o mundo atual em que vivemos, junto às outras questões vitais. Modificações que deverão ocorre através de uma pedagogia que atenda as necessidades 
dos três domínios do sujeito da ação, ou sejam, a prática do pensamento lógico dos códigos do jogo e suas relações com as coisas exatas; as relações humanas de forma a valorizar as situações onde novas emoções aparecem e devem ser reforçadas para a alegria, diminuindo ao máximo as frustrações; o envolvimento do corpo, através dos movimentos das modalidades esportivas, utilizando as habilidades herdadas geneticamente, oferecendo novas formas de movimentos a fim de enriquecer o vocabulário motor. Todas as capacidades desenvolvidas serão acompanhadas do crescimento através do espírito crítico e de grande capacidade de criatividade. Ainda nos referindo a Carvalho (1998, p.13)

Ainda bem que há dissidentes, alguns já desterritorializados, que abdicaram de sua competência disciplinar, para transmitir a alunos, amigos e amantes, uma forma mais dionisíaca de se entender a natureza e a cultura.

\section{Esporte Participação}

Sua finalidade primeira deve ser o prazer da ação (lúdico) a favor do bem estar individual, coletivo e social. Estas passagens sugerem experiências do domínio individual para a participação coletiva. Seu principal objetivo é o de preparar o sujeito para que tenha consciência do valor destes conteúdos culturais do esporte utilizado no tempo livre, fora do trabalho com o propósito de descontração, de diversão e de desenvolvimento pessoal que só pode ser entendido se for para a saúde das relações sociais.

A participação também sugere a popularização e a desmistificação da prática que, muitas vezes, não ocorre por falta de conhecimento da possibilidade de acesso, de suposta dificuldade de aprendizagem e da falta de oferecimento pelos poderes públicos, privados e mistos. Aqui se verifica o verdadeiro sentido de democracia.

\section{Esporte de Alta Competição}

Esta dimensão de prática do esporte é a de maior reconhecimento em nossa sociedade. Ainda é considerada importante no contexto sócio cultural e econômico devido aos efeitos que exerce sobre as organizações esportivas que estão sob a égide. 
Contudo, para atendimento a esta forma de desenvolvimento esportivo, é exigido; um modelo de organização, com alto grau de complexidade, caso contrário percebe-se incoerência de propósitos; recursos humanos com muito conhecimento técnico, recursos físicos e materiais apresentando alta tecnologia, coerente com as propostas de atendimento às exigências apontadas pelas entidades que promovem a alta competição; recursos financeiros suficientes para montagem de todo cenário para que se aproxime dos ambientes utilizados nos eventos locais, regionais, nacionais e internacionais preparados para receber pessoas especiais da alta competição. Trazer, em seus propósitos, o favorecimento dos talentos esportivos, reforçando a capacidade de auto-superação e também a superação dos ambientes pelos atletas.

Entende-se que hoje, o esporte de alta competição funciona na dependência da existência da grande mídia, pois, sem ela, como a exemplo do fenômeno Maria Ester Bueno nem o benefício de atingir a grande massa não teriam. Sob um rótulo de "espetáculo", o esporte de alto rendimento tem como estratégia o atleta veículo de divulgação, propagador de um logotipo subliminarmente assimilado por todos.

\section{Conclusão}

A responsabilidade com o desenvolvimento e manutenção, como também a transformação que a prática do jogo de tênis vem necessitando, a favor de sua facilitação em benefício da população nas várias dimensões sociais, certamente, recai sobre estruturas físicas e humanas competentes. Logicamente que todas as organizações existentes para o trabalho prático, poderá se utilizar recursos humanos auxiliares em seu quadro, respeitando hierarquias profissionais de ação didática. Nas ações informais, o trabalho pode ser organizado sem a presença do profissional da área, acreditando-se na eficácia das ações para a autonomia dos usuários. Cada vez mais, os consumidores da prática do tênis de campo, vêm exigindo qualidade no oferecimento dos serviços prestados pelas organizações e melhores espaços específicos para a prática do jogo. Isto obrigará a um aperfeiçoamento cada vez maior de pessoas especializadas e competentes. 


\section{Referências Bibliográficas}

BENTO, J. O. O outro lado do desporto. Lisboa: Campo das Letras, 1995.

CARVALHO, A. M. de Educação Física e desenvolvimento. Lisboa: Compendium, 1980 .

CARVALHO, E. A. Ética: solidariedade e complexidade. São Paulo: Palas Athenas, 1998.

DAÓLIO, J. Educação Física e o conceito de cultura. Campinas: Autores Associados, 2004.

DUMAZEDIER, J. Valores e conteúdos culturais do lazer. São Paulo: SESC, 1980.

DUNNING, E. A busca da excitação. Lisboa: Difusão Editorial, 1986.

ORLICK, T. Vencendo a competição. São Paulo: Circulo do Livro, 1971.

PARKER, S. A sociologia do lazer. Rio de Janeiro: Zahar, 1978.

SANTOS, J. L. dos. O que é cultura. São Paulo: Brasiliense, 1993.

STUCCHI, S. Esporte de lazer: conceito e reflexões. Campinas: UNICAMP/FEF: GEEL, 2004. (no prelo).

TUBINO, M. J. G. Dimensões sociais do esporte. São Paulo: Cortez: Autores Associados, 1992. 